\title{
Non-thermal Oxygen-Helium Plasma Modification and Regeneration of Sawdust Biochar to Promote Aniline Removal
}

\author{
Huiyan Zhang, ${ }^{*}$ Jiajun Yu and Jiawei Wang
}

\begin{abstract}
The pollutant adsorption performance of produced biochar could be dramatically improved by low-energy cost plasma technology. Non-thermal oxygen-helium plasma was proposed to modify and regenerate sawdust biochar by enhancing oxygen-containing functional groups on the surface of the biochar. The effect of discharge gas, discharge time, carrier gas flow rate, and discharge power on the product's performance for aniline removal was investigated in detail. Scanning electron microscope (SEM) analysis showed that plasma treatment could etch the surface of biochar and form pits. Fourier transform infrared spectroscopy (FT-IR), X-ray photoelectron spectroscopy (XPS), and elemental analysis showed that the oxygen content of the modified biochar increased from $20.15 \%$ to $23.88 \%$, and more oxygen-containing functional groups were formed on the surface. After the oxygen-helium non-thermal plasma modification, the aniline adsorption capacity of the biochar increased by about 23.5\%. Meanwhile, water vapor was introduced into the plasma regeneration system. The regeneration ratio maintained at $80 \%$ after ten times of regeneration, which was much higher than the thermal regeneration ratio of $55.28 \%$. It was speculated that the adsorption mechanism was that the amino group of aniline forms a hydrogen bond with a carbonyl group and a carboxyl group, and the carbonyl group forms an electron donor-acceptor structure with the aromatic ring of aniline.
\end{abstract}

Keywords: Biochar; Oxygen-helium plasma; Surface modification and regeneration; Functional group; Aniline removal.

Received: 12 October 2021; Accepted: 1 January 2022.

Article type: Research article.

\section{Introduction}

Aniline is an important chemical substance and is widely used in many industries such as dyes, medicine, and pesticides. But according to the World Health Organization report results, aniline is classified as a carcinogen. ${ }^{[1]}$ Considering its harm to organisms, China has very strict requirements on the emission of aniline (the maximum allowable emission concentration of aniline in the first level standard is $1.0 \mathrm{mg} / \mathrm{L}, \mathrm{GB} 8978-1996$ ). Aniline wastewater treatments are commonly needed in industrial processes including biodegradation, ${ }^{[1]}$ chemical oxidation, ${ }^{[2]}$ electrocatalytic oxidation ${ }^{[3]}$ and adsorption. ${ }^{[4]}$ Adsorption one of the most effective environmental control technologies is widely used in the food, beverage, pharmaceutical, and chemical industries. The usual adsorbents are molecular sieves, silica gel, activated aluminum, polymer adsorbents, biosorbents, and carbon materials. ${ }^{[5]}$ Biological biochar which is produced by biomass pyrolysis is an excellent

Key Laboratory of Energy Thermal Conversion and Control of Ministry of Education, School of Energy and Environment, Southeast University, Nanjing 210096, China.

*Email: hyzhang@seu.edu.cn (H. Zhang) adsorbent that is prepared by physical or chemical activation and has a large specific surface and rich pore structures. ${ }^{[6]}$ Therefore, the use of agricultural and forestry wastes such as sawdust, straw, and other cheap raw materials to prepare highperformance biochar has become one of the hottest topics. The specific surface area and the number of surface functional groups of biochar can be effectively increased by modification, thereby improving the adsorption capacity and adsorption selectivity of biochar. ${ }^{[7]}$

Common modification methods include acid or alkali treatment, ${ }^{[8]}$ microwave treatment, ${ }^{[9]}$ ozone treatment, ${ }^{[10]}$ and biological modification. ${ }^{[11]}$ In the traditional modification method, the adsorption material is usually treated by impregnation, which is the addition of a chemical reagent to increase the number of active sites on the surface. But the operation of this method is complicated, the waste water will cause secondary pollution to the environment, and the heating method used in the modification is inefficient and uneconomical. ${ }^{[12]}$ Therefore, attention should be focused on the development of simpler and greener modification technologies. The plasma device has the characteristics of rapid start and stop, and can be modified in a short time. 
Plasma modification is a kind of cheap and green physical modification, which is carried out at room temperature by the reaction of active substances produced by gas ionization. ${ }^{[13,14]}$ Plasma is the fourth state of matter, which is composed of ions, electrons, excited state molecules, free radicals, and other active particles. ${ }^{[15]}$ Artificially produced plasma in a laboratory or industry is usually produced by electrons accelerated by an electric field. ${ }^{[16,17]}$ High kinetic energy electrons in nonthermal plasma can affect the physical structure of the material and the active substance generated by the plasma can break the chemical bond, oxidize or reduce the material in different gases. ${ }^{[18,19]}$ In non-thermal plasma, the gas is ionized, producing electrons with very high kinetic energy and very high temperatures $\left(10^{5} \mathrm{~K}\right)$, but the temperature of the molecules, atoms, and ions was close to room temperature. ${ }^{[20]}$ There have been some latest researches on plasma-modified carbon materials, which found that plasma modification could increase the adsorption capacity of metal ions. ${ }^{[21]}$ For example, when biochar was treated with $\mathrm{NH}_{3}$ plasma, the emission intensity of $\mathrm{NH}$ species on the surface of the biochar showed a dependency on the discharge intensity. ${ }^{[22]} \mathrm{O}_{2}$ and $\mathrm{N}_{2}$ plasma modification enhanced the formation of oxygen-containing functional groups and nitrogen-containing functional groups on the Activated carbon (AC) surface, respectively. ${ }^{[23]}$ And $\mathrm{H}_{2} \mathrm{~S}$ plasma treatment can increase the S-containing active sites of activated carbon and enhance its removal efficiency of $\mathrm{Hg}^{0}{ }^{[24]}$ However, when air plasma was used to oxidize the surface of biochar to achieve modification, $\mathrm{N}_{2}$ ionization is relatively difficult, which limits the modification effect. ${ }^{[25]}$ Because the He $\left(2^{3} \mathrm{~S}\right)$ state has large internal energy $(19.8 \mathrm{eV})$, the penning ionization of many molecules can be realized by the helium metastable state. ${ }^{[26]}$ Helium-oxygen plasma as oxygen as an electronegative gas is an issue but where strong oxidizing species generation could be expected. ${ }^{[27,28]}$ Compared with gases such as nitrogen, helium is easier to excite and generate plasma, and can effectively improve the stability and uniformity of the discharge. ${ }^{[29]}$

In this paper, we show an effective modification and regeneration method. Sawdust biochar was modified by oxygen-helium plasma, and oxygen-containing functional groups were added to the surface of the biochar to enhance the adsorption performance of biochar for organic pollutants. From the plasma modification and regeneration process, the effects of discharge gas, discharge time, carrier gas flow rate, water vapor addition, and discharge power were studied. Finally, the possible modification mechanism of non-thermal plasma was deduced, and the adsorption mechanism of aniline on the modified biochar was discussed from the aspects of physical adsorption and chemical adsorption based on the above results. In this work, the chemical reagents involved in the traditional biochar activation process were avoided, and high-performance biochar was prepared in an environmentally sound manner.

\section{Experimental}

\subsection{Sample preparations}

In the experiment, the sawdust was selected as the raw material and dried at $85{ }^{\circ} \mathrm{C}$ for 24 hours. The sawdust was placed in a fixed bed pyrolysis furnace, and nitrogen (200 $\mathrm{mL} / \mathrm{min}$ ) flowed into the exhaust air in the reactor. Then the sawdust was pyrolyzed at $400{ }^{\circ} \mathrm{C}$ for $1 \mathrm{~h}$ to form biochar and activated at $800{ }^{\circ} \mathrm{C}$ by the steam activation method. After grinding, carbon powder with 180-200 mesh size was obtained and used for modification.

\subsubsection{Modification experiments}

In each experiment, biochar was placed in a dielectric barrier discharge (DBD) reactor for modification. Different gases were used to modify the biochar, including oxygen, helium, oxygen-helium $\left(\mathrm{O}_{2} / \mathrm{He}=0.21 / 0.79\right)$, nitrogen, and air. The mixed gas was used to exhaust the air in the reactor, and then the transformer and power supply were started and adjusted to the appropriate voltage and alternating current frequency so that in the reaction zone would appear a stable light-blue discharge phenomenon, and the oscilloscope would show a stable Lissajous-Figure. The plasma parameters were adjusted and the biochar was treated. The conditions of biochar plasma modification are shown in Table 1.

Table 1. The typical conditions of biochar plasma modification.

\begin{tabular}{lllll}
\hline Sample & $\begin{array}{l}\text { Discharge } \\
\text { gas }\end{array}$ & $\begin{array}{l}\text { Time } \\
(\mathrm{min})\end{array}$ & $\begin{array}{l}\text { Gas } \\
(\mathrm{mL} / \mathrm{min})\end{array}$ & $\begin{array}{l}\text { flow } \\
\text { power }(\mathrm{W})\end{array}$ \\
\hline ACO0 & $\backslash$ & $\backslash$ & $\backslash$ & $\backslash$ \\
$\mathrm{ACO} 3$ & $\mathrm{O}_{2}-\mathrm{He}$ & 3 & 100 & 48.8 \\
ACO15 & $\mathrm{O}_{2}-\mathrm{He}$ & 15 & 100 & 48.8 \\
AC- $\mathrm{L}$ & $\mathrm{O}_{2}-\mathrm{He}$ & 15 & 100 & 34.9 \\
AC-H & $\mathrm{O}_{2}-\mathrm{He}$ & 15 & 100 & 64.8 \\
$\mathrm{AC}-$ & $\mathrm{He}$ & 15 & 100 & 48.8 \\
$\mathrm{He} 15$ & & & &
\end{tabular}

\subsubsection{Regeneration experiments}

The adsorbed and saturated ACO15 was selected as the regenerative raw material. The solid product obtained by extraction and filtration separation (saturated ACO15) was naturally air-dried at room temperature. The power frequency was $10 \mathrm{kHz}$ to complete the pre-activation of the biochar surface. Firstly, the injection pump and the steam stove were started with a water flow of $0-20 \mu \mathrm{L} / \mathrm{min}$ and a vapor exit temperature of $170^{\circ} \mathrm{C}$. Then, the peak voltage and power frequency were adjusted and the discharge maintained stable for a period of time.

\subsection{DBD plasma device}

As shown in Fig. 1, the high voltage power supply produces a high voltage sine wave, and the gas was ionized in the reaction chamber to generate plasma. The oscilloscope probe was connected to the test port and used to measure the applied voltage amplitude, frequency and current, and the tail gas was 


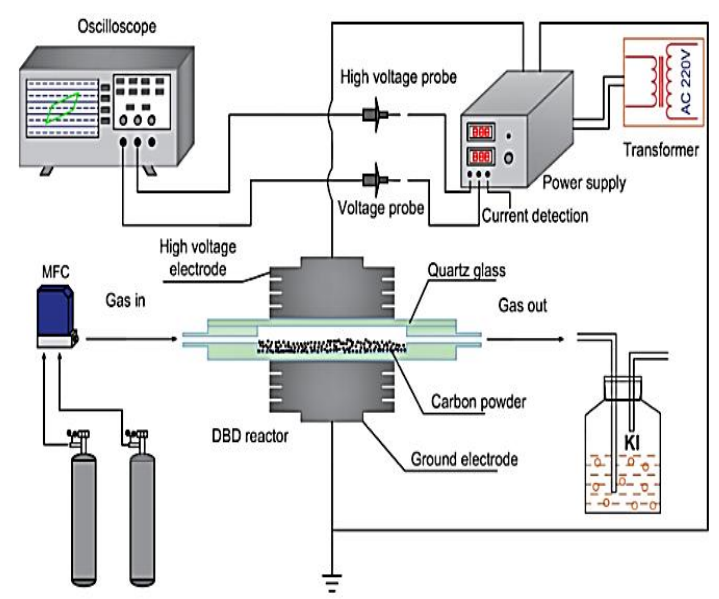

Fig. 1 Schematic diagram of the dielectric barrier discharge experimental device for biochar modification and regeneration.

absorbed by a KI Solution. The DBD reactor was made of quartz with a diameter of $90 \mathrm{~mm}$ and a thickness of $1 \mathrm{~mm}$, and the gap in the reaction chamber was $8 \mathrm{~mm}$.

Figure 2 shows the Lissajous figure with the sample voltage as the $\mathrm{x}$-axis and the sample current integral as the $\mathrm{y}$ axis. The processes $\mathrm{A}$ to $\mathrm{B}$ and $\mathrm{C}$ to $\mathrm{D}$ are discharge extinguished. In this process, the power supply charges the quartz plate and gas, and the linear slope is equal to the sum of the capacitance values of the quartz plate and gas. The slope is equal to the sum of the capacitance of the quartz plate and gas. $\mathrm{B}$ to $\mathrm{C}, \mathrm{D}$ to $\mathrm{A}$ is the discharge, the gas is broken down to produce the plasma, and the slope is equal to the capacitance of the quartz plate. ${ }^{[30]}$ The power acting on the reactor can be calculated according to the Lissajous figure:

$P_{\text {out }}=K_{X} \cdot K_{Y} \cdot \frac{f}{n} \cdot \int_{0}^{n T} U_{t} \cdot I_{t} d t=K_{X} \cdot K_{Y} \cdot \frac{f}{n} \cdot \int_{0}^{n T} U_{t} d q$

$K_{X}$ and $K_{Y}$ are the attenuation coefficients of the oscilloscope sampling channels 1 and 2, the sampling capacitance is $0.47 \mu \mathrm{F}, f$ is the frequency, and $\mathrm{n}$ is the number of cycles. AC-L, ACO15, and AC-H were the samples modified at different power, the integral areas of their Lissajous figures were 19.4, 26.8, 34.3, and the final calculated power values were $34.9 \mathrm{~W}, 48.8 \mathrm{~W}, 64.8 \mathrm{~W}$.

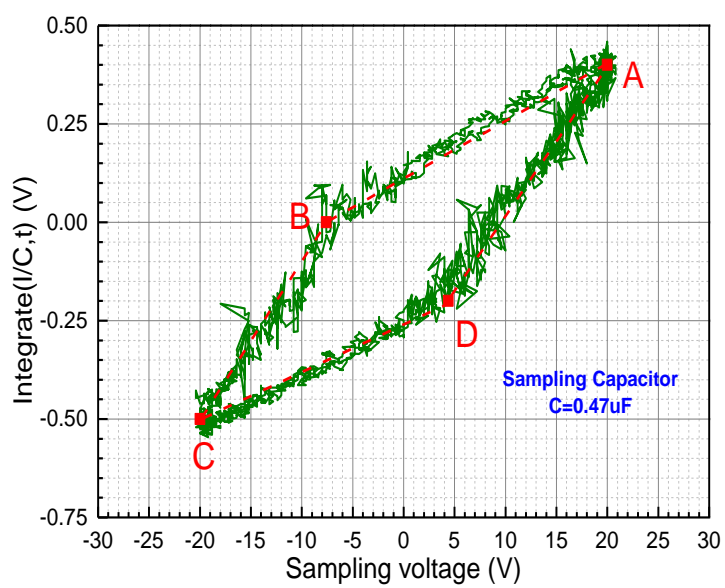

Fig. 2 Lissajous diagram of the dielectric barrier discharge characteristics.

\subsection{Adsorption experiments}

The adsorbate selected for the adsorption test was aniline with an initial concentration of $400 \mathrm{mg} / \mathrm{L}$. The volume of the adsorbate solution was $50 \mathrm{~mL}$, the temperature was controlled at $30 \pm 0.1{ }^{\circ} \mathrm{C}$, and the agitation speed of the rotary shaker was $130 \mathrm{rpm}$. After $24 \mathrm{~h}$ of continuous adsorption, the filter paper was used to quickly separate solids and liquids. The aniline concentration was tested by an ultraviolet spectrophotometer at $280 \mathrm{~nm}$. The absorbance of the standard solution was measured, and a standard curve was drawn to ensure an $\mathrm{R}^{2}$ value of 0.999 or more. The absorbance was taken into the standard curve to calculate the concentration of the adsorbed solution. The amount of adsorption and removal efficiency was calculated using the following formula:

$$
\begin{aligned}
q_{m} & =\frac{V \cdot\left(C_{0}-C_{1}\right)}{m} \\
\eta & =\frac{C_{0}-C_{1}}{C_{0}}
\end{aligned}
$$

where $C_{0}$ and $C_{1}$ were the concentration of the solution before and after adsorption, $V$ was the volume of the adsorbate, and $m$ was the input mass of the carbon.

The regeneration ratio can be calculated as follows:

$$
\text { Regeneration ratio }=\frac{q_{r}}{q_{m}} \times 100 \%
$$

where, $q_{r}$ is the saturated adsorption amount of regenerated carbon, and $q_{m}$ is the saturated adsorption amount of biochar $\mathrm{ACO} 15$.

\subsection{Characterization methods}

The specific surface area and pore distribution were analyzed by Brunner-Emmet-Teller (BET) (Gold APP V-Sorb4800s), and the nitrogen adsorption curves of the samples at $77 \mathrm{~K}$ were measured. The structure and morphology of the samples were analyzed by SEM (JSM-7800F Japan). The organic element analyzer (Vario Macro Cube) was used to measure the relative content of $\mathrm{C}, \mathrm{H}$, and $\mathrm{N}$ in the samples. The functional groups on the surface of samples were identified by FT-IR (Thermo Scientific Nicolet iS 50) and XPS (Thermo Scientific KAlpha $^{+}$). In the FT-IR test, the background was captured using high-purity $\mathrm{KBr}$, and the scanning spectrum range was 500 $4000 \mathrm{~cm}^{-1}$. In the XPS test, the analyzer was a $180^{\circ}$ dual-focus hemisphere analyzer with a vacuum of $\leq 2 \times 10^{-7} \mathrm{mbar}$ in the analysis chamber.

\section{Results and discussion}

\subsection{Biochar characterization3.1.1 Elemental analysis}

Elemental analysis of the original and modified biochar by plasma is shown in Table 2. The samples in the table are treated with $\mathrm{O}_{2}-\mathrm{He}$ plasma. The gas flow rate is $100 \mathrm{ml} / \mathrm{min}$ and the discharge power is $48.8 \mathrm{~W}$. The number represents plasma treatment time. The oxygen content after the modification increased from $20.15 \%$ to $23.88 \%$, and the carbon content decreased from $76.81 \%$ to $73.65 \%$. The plasma contained $\mathrm{O}$ radicals, which would react with the biochar, allowing $\mathrm{O}$ to be loaded onto the biochar, increasing the oxygen content. ${ }^{[31]}$ 
Table 2. Elemental analysis of the original and modified biochar by non-thermal plasma.

\begin{tabular}{lcccc}
\hline \multirow{2}{*}{ Sample } & \multicolumn{4}{c}{ Ultimate analysis (wt.\%) } \\
\cline { 2 - 5 } & $\mathrm{C}$ & $\mathrm{H}$ & $\mathrm{O}$ & $\mathrm{N}$ \\
\hline ACO0 & 76.81 & 2.70 & 20.15 & $<0.3$ \\
ACO3 & 76.58 & 2.64 & 20.44 & $<0.3$ \\
ACO6 & 76.15 & 2.62 & 20.79 & $<0.3$ \\
ACO10 & 75.91 & 2.50 & 21.25 & $<0.3$ \\
ACO15 & 73.65 & 2.14 & 23.88 & $<0.3$ \\
ACO20 & 74.68 & 2.24 & 22.74 & $<0.3$ \\
ACO40 & 74.67 & 2.33 & 22.68 & $<0.3$ \\
\hline
\end{tabular}

\subsubsection{XPS analysis}

Figure 3 shows the high-resolution XPS spectra of $\mathrm{C}_{1 \mathrm{~s}}$ of the sample. The spectrum was decomposed into four peaks and the best-fitting result was obtained. The binding energy of 284.6 (peak A), 285.8 (peak B), 287.1 (peak C), and 289.1 (peak D) correspond to $\mathrm{C}-\mathrm{C}, \mathrm{C}-\mathrm{O}$ (alcohol and ether groups), $\mathrm{C}=\mathrm{O}$ (carbonyl groups), $\mathrm{O}-\mathrm{C}=\mathrm{O}$ (carboxylic and ester groups), ${ }^{[32,33]}$ respectively. Table 3 lists the relative contents of
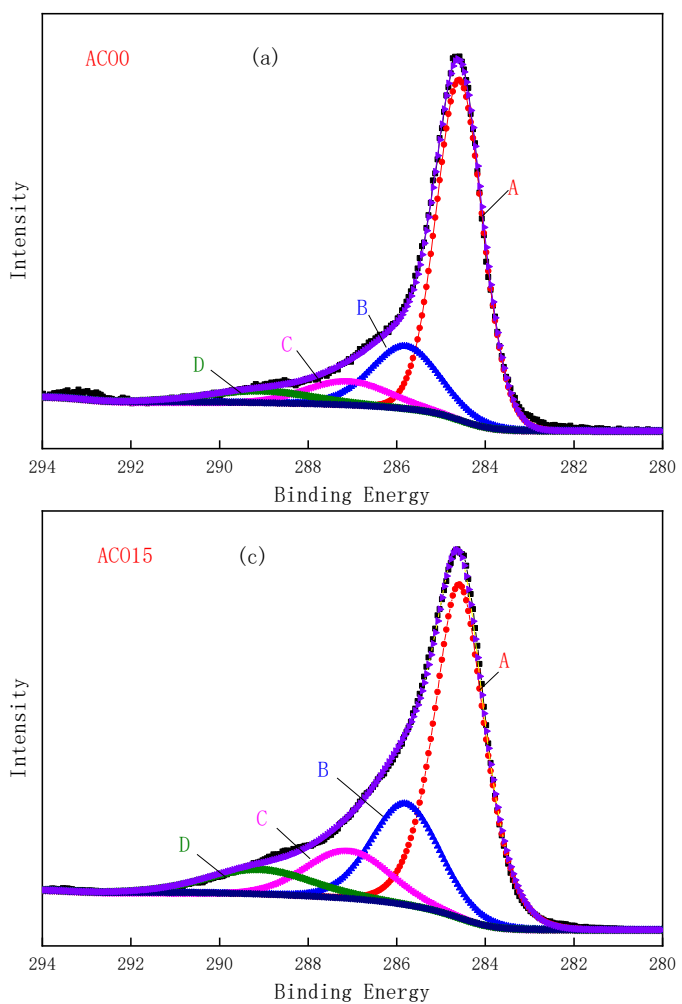

Fig. 3 XPS spectra of the C1s of (a) ACO0

Table 3. Relative content of oxygen-containing functional groups of the samples

\begin{tabular}{ccccccccc}
\hline $\begin{array}{c}\text { Functional } \\
\text { groups }\end{array}$ & $\begin{array}{c}\text { Binding } \\
\text { energy }(\mathrm{eV})\end{array}$ & $\mathrm{ACO} 0$ & $\mathrm{ACO} 3$ & $\mathrm{ACO} 6$ & $\mathrm{ACO} 10$ & $\mathrm{ACO} 15$ & $\mathrm{ACO} 20$ & $\mathrm{ACO} 40$ \\
\hline $\mathrm{C}-\mathrm{C}$ & 284.6 & 67.1 & 63.5 & 59.6 & 55.8 & 54.6 & 61.7 & 61.7 \\
$\mathrm{C}-\mathrm{O}$ & 285.8 & 18.4 & 19.4 & 22.4 & 22.6 & 20.2 & 19.8 & 18.9 \\
$\mathrm{C}=\mathrm{O}$ & 287.1 & 8.7 & 9.5 & 10.1 & 13.1 & 15.9 & 10.0 & 9.9 \\
$\mathrm{O}-\mathrm{C}=\mathrm{O}$ & 289.1 & 5.4 & 7.6 & 7.9 & 8.5 & 8.6 & 8.6 & 9.6 \\
\hline
\end{tabular}

various oxygen-containing functional groups in different samples. Considering the peak area and the sensitivity factor of each atom evaluated by XPS peak splitting software, as well as the uncertainty of experimental optical data, the typical uncertainty of quantitative XPS is about $10 \%{ }^{\left[{ }^{[34]}\right.}$ It is found that the number of $\mathrm{C}-\mathrm{O}, \mathrm{C}=\mathrm{O}$, and $\mathrm{O}-\mathrm{C}=\mathrm{O}$ increases to a certain extent after oxygen plasma treatment, which is consistent with the change in oxygen content. As the modification time increased, the amount of $\mathrm{C}=\mathrm{O}$ began to decrease after 15 min, however, the number of $\mathrm{O}-\mathrm{C}=\mathrm{O}$ continued to increase, which might be related to the local thermal effect and the interaction of energetic particles produced by the plasma, promoting the conversion of carbonyl groups to carboxyl groups.

\subsubsection{FT-IR analysis}

Figure 4 shows the FT-IR spectrum of ACO0, AC-He15, and ACO15. For carbon materials, the absorption band at $1080 \mathrm{~cm}^{-}$ ${ }^{1}$ corresponds to $\mathrm{C}-\mathrm{O}$ and the absorption band at $1160 \mathrm{~cm}^{-1}$ corresponds to $\mathrm{C}-\mathrm{O}-\mathrm{C}$. The absorption band at $1580 \mathrm{~cm}^{-1}$ is the $\mathrm{C}-\mathrm{C}$ stretching vibration in the aromatic ring. The absorption bands at $1530 \mathrm{~cm}^{-1}$ and $1700 \mathrm{~cm}^{-1}$ are generally
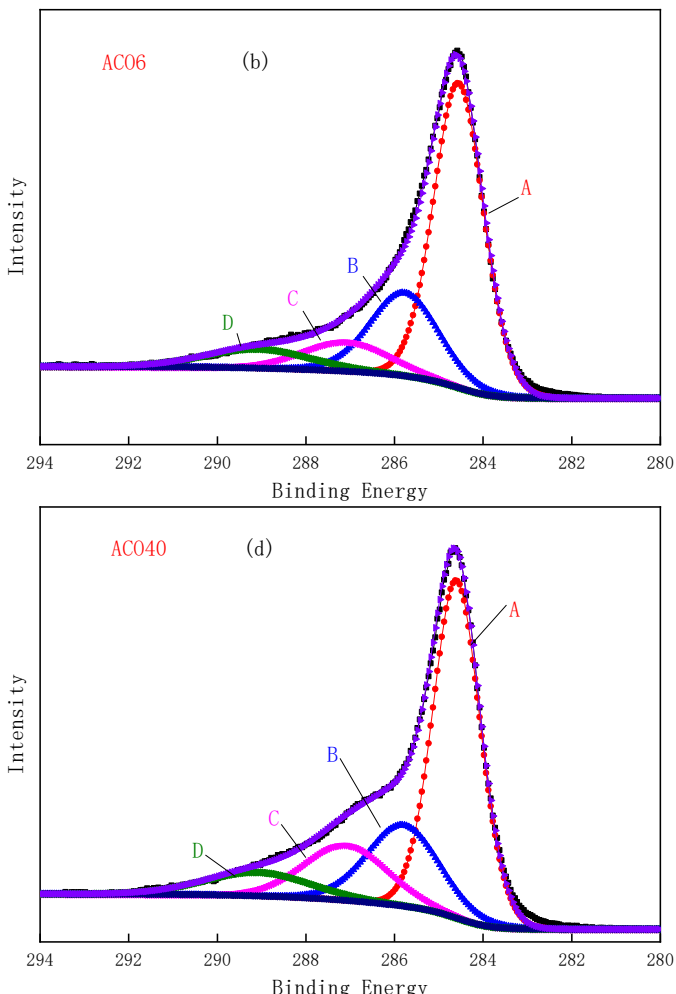

; (b) ACO6; (c) ACO15 and (d) ACO40. 
considered to be the result of the stretching vibration of $\mathrm{C}=\mathrm{O}$ in ketones, aldehydes, lactones, and carboxyl groups, and the noting that the infrared spectra of the He plasma-modified biochar had little change compared with the original biochar, so it was believed that the oxygen in the atmosphere reacted with the biochar to form more oxygen-containing functional groups, rather than the plasma promoted the conversion of the oxygen in the biochar to oxygen-containing functional groups on the surface of the biochar.

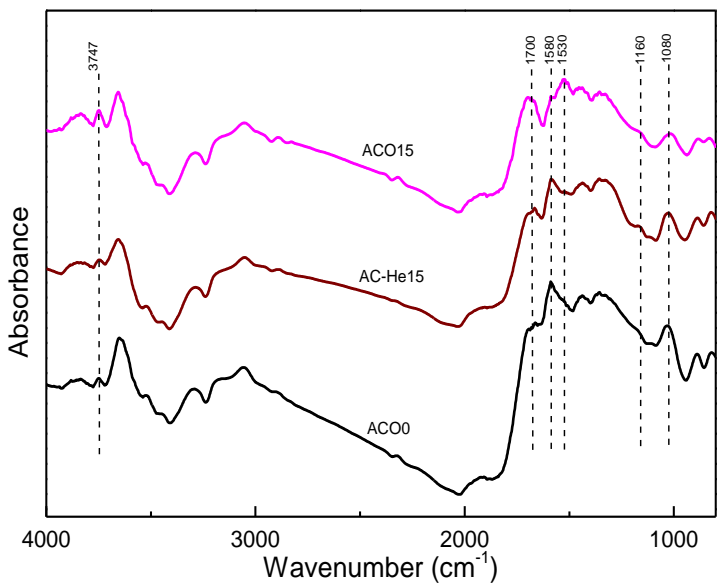

Fig. 4 FT-IR of the original and modified biochar by non-thermal plasma.

\subsubsection{Boehm titration}

Figure 5 shows the number of oxygen-containing functional groups on the biochar surface obtained by Boehm titration at different treatment times. The carbonyl group is considered to be a Lewis base. The change of the basic group obtained by Boehm titration in this study is consistent with the observation for carbonyl groups in the literature. ${ }^{[38]}$ With the increase in the plasma treatment time, the number of carboxylic acids increased, and the number of lactone groups did not change much. The ratio of the total acidic groups to the total number of groups increased from $44.7 \%$ to $55.3 \%$. The changes in functional groups obtained by Boehm titration are consistent with the FT-IR and XPS analyses, which supports the previous experimental conclusions.

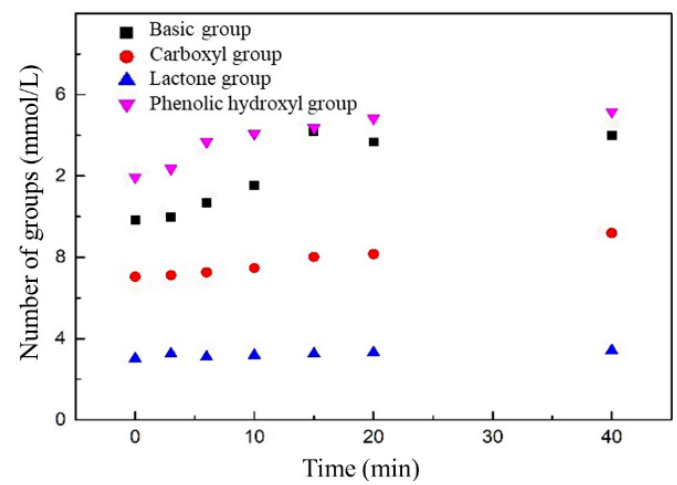

Fig. 5 Variation diagram of oxygen-containing functional groups on the biochar surface (Discharge gas: $\mathrm{O}_{2}-\mathrm{He}$, Gas flow: 100 $\mathrm{mL} / \mathrm{min}$, Discharge power: 48.8 ).

\subsubsection{Specific surface area and porosity}

The specific surface area and porosity of biochar will affect the adsorption capacity. The nitrogen adsorption and desorption curves shown in Fig. 6 belong to the fourth type of adsorption curve. The presence of $\mathrm{H}_{3}$ hysteresis rings indicates that the biochar has more mesopores and no obvious saturated adsorption. ${ }^{[39]}$ The biochar used in this study is made by physical activation, which is presumed to be a fractured pore material. It can be seen from Fig. 6 that the pore diameter of biochar is mainly distributed between 2-10 nm, which indicates that the pores in biochar are mainly mesopores. It can be seen from the figure that after plasma treatment, the average pore diameter of biochar decreases and the number of micropores slightly increases, which is consistent with previous studies. ${ }^{[31]}$ As shown in Table 4, with the increase of plasma treatment time, the specific surface area of activated carbon first increases and then decreases, and the pore volume also shows the same change. When the treatment time is $\leq 10$ min, the plasma opens some pores and the micropores are released. At the time, plasma shows the characteristics of poreforming. When the treatment time further increases, the pore structure collapses. Some pores are damaged, and the specific surface area decreases.

Table 4. Specific surface area and pore parameters of biochar with different treatment times.

\begin{tabular}{crcc}
\hline Sample $^{\mathrm{a}}$ & SBET $\left(\mathrm{m}^{2} / \mathrm{g}\right)$ & $\begin{array}{l}\text { Pore volume } \\
\left(\mathrm{cm}^{3} / \mathrm{g}\right)\end{array}$ & $\begin{array}{l}\text { Mean pore size } \\
(\mathrm{nm})\end{array}$ \\
\hline ACO0 & 857.48 & 0.804 & 4.01 \\
ACO3 & 869.99 & 0.832 & 3.82 \\
ACO6 & 881.57 & 0.859 & 3.75 \\
ACO10 & 920.81 & 0.861 & 3.78 \\
ACO15 & 908.17 & 0.860 & 4.31 \\
ACO20 & 896.47 & 0.845 & 4.25 \\
ACO40 & 891.85 & 0.841 & 4.25 \\
\hline
\end{tabular}

\subsubsection{Surface topography}

Figure 7 shows the SEM diagrams of the samples. Figs. 7a and b correspond to ACO0, Figs. 7c and d correspond to ACO15, Fig. e corresponds to ACO40, and Fig. 7f corresponds to AC$\mathrm{H}$. It could be found that the surface of the biochar after plasma modification became rougher. The reason could be that a large number of the active particles in the plasma, including highenergy electrons, ions, and neutral particles can bombard the surface of the biochar, and the local thermal effect caused by the streamer generated during discharge causes the atom to evaporate, causing some pits on the surface of the material. ${ }^{[40]}$ Comparing the SEM images in Figs. 7c and e, it was found that the roughness of the surface of biochar increased as the treatment time increased. Compared with Figs. $7 \mathrm{~b}$ and d, it was found that the plasma not only etched the surface of the biochar but also had a positive effect on clearing blocked channels. The SEM image in Panel $\mathrm{f}$ shows that when the 

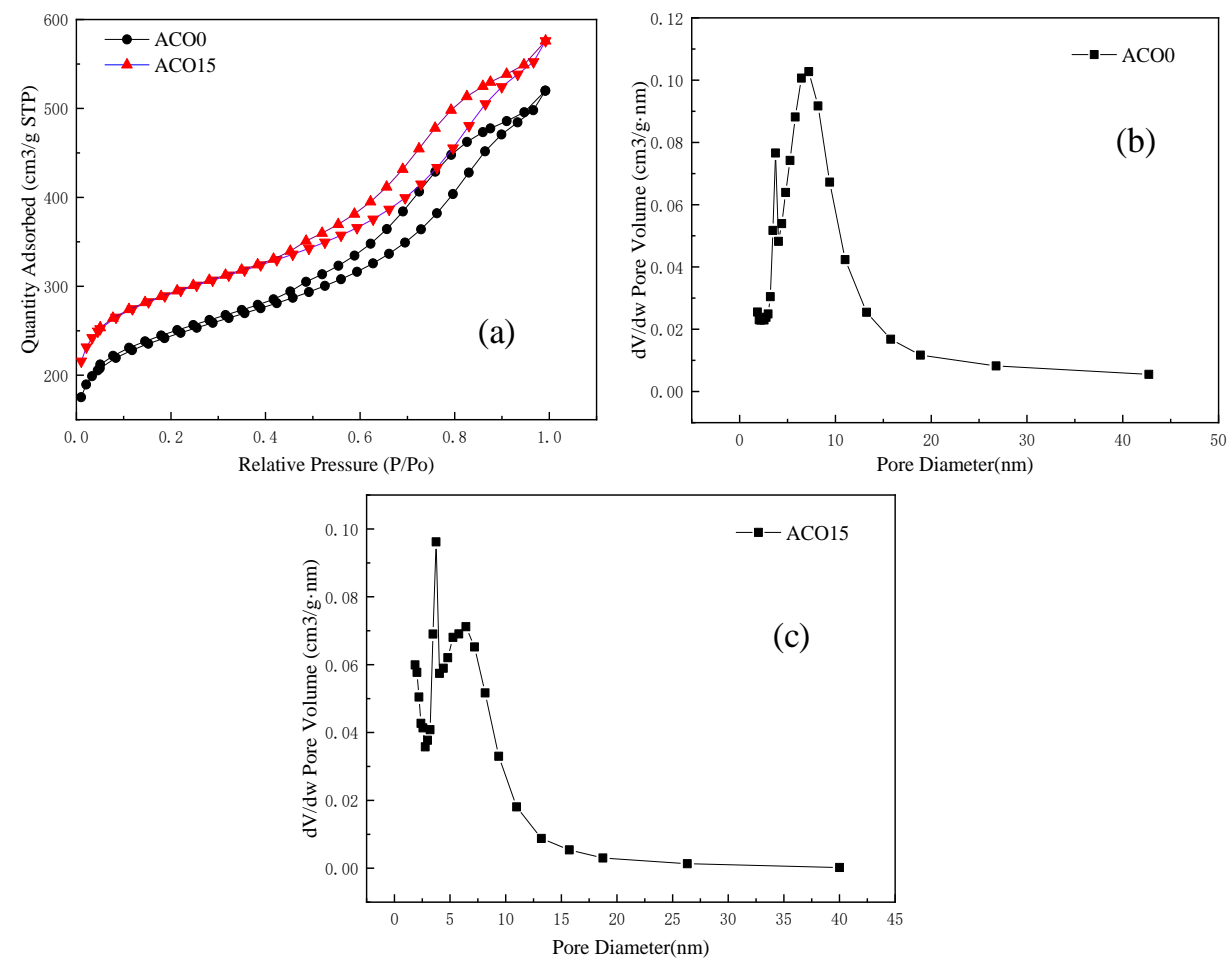

Fig. 6 (a) Nitrogen adsorption and desorption curve of biochar before and after modification; (b) and (c) Pore size distribution map before and after modification.

loading power was high, the degree of etching on the surface of the biochar would further increase, and the plasma might cause some negative effects on the surface of the biochar. ${ }^{[37]}$ However, in most cases, the plasma did not cause serious damage to the material compared to chemical modification and had little effect on the physical structure of the material. Therefore, it could be considered that the etching effect of the plasma was very slight at a suitable discharge power. ${ }^{[4]}$

\subsection{Adsorption characteristic analysis}

3.2.1 Influence of discharge gas type on aniline adsorption. In order to study the effect of different plasma atmospheres on the adsorption of aniline on biochar, the biochar was treated with plasmas of oxygen, nitrogen, air, helium, and oxygenhelium. It can be seen from Fig. 8 that the adsorption capacities of biochar after five plasma treatments of oxygen, nitrogen, air, helium, and oxygen-helium to aniline were $132.56,116.81,130.14,118.19$, and $146.5 \mathrm{mg} / \mathrm{g}$, respectively. After oxygen, air, and helium-oxygen plasma treatments, the biochar had an increased adsorption capacity for aniline, while the adsorption capacity of helium plasma and nitrogen plasmamodified biochar for aniline has not changed. Oxygencontaining functional groups such as hydroxyl on the surface of biochar can promote the adsorption of aniline. ${ }^{[42]}$ The plasma provided the energy required for the reaction and promoted the conversion of oxygen elements into oxygencontaining functional groups, and the plasma modification occurred on the surface of the biochar. By adding oxygen from the outside, the performance can effectively improve the adsorption capacity of the biochar for aniline. The adsorption
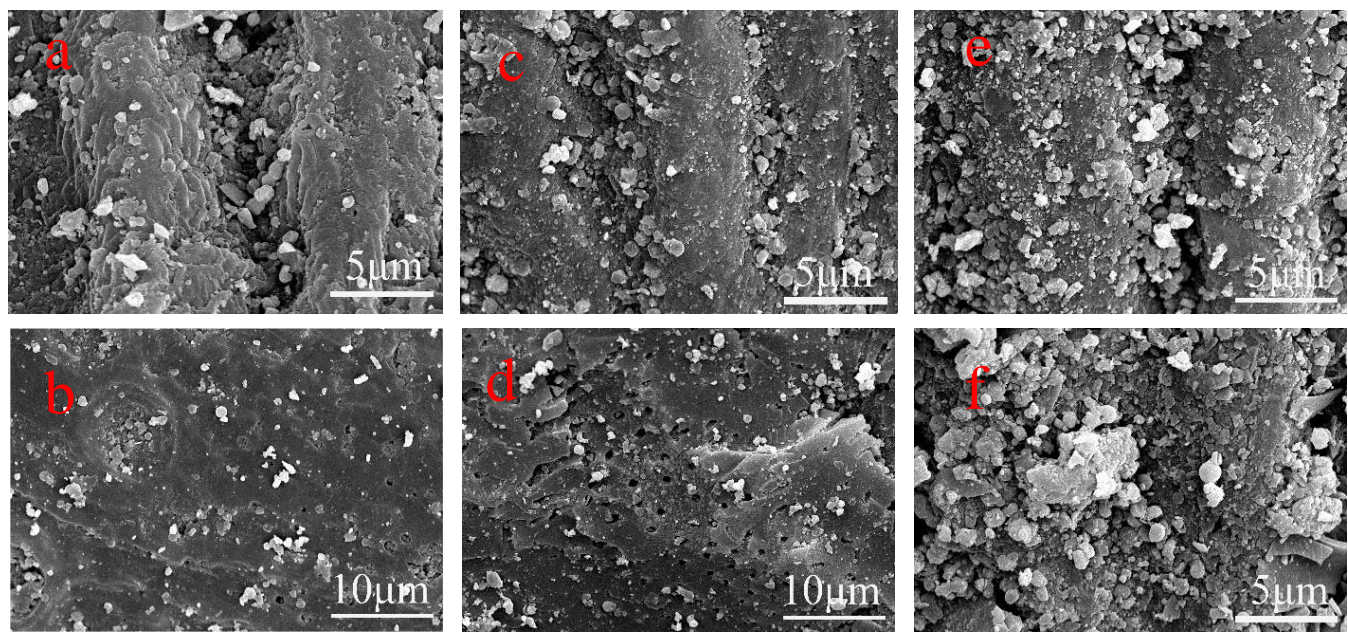

Fig. 7 SEM images of the samples: (a) (b)ACO 0; (c) (d) ACO 15; (e)ACO 40; (f)AC-H. 


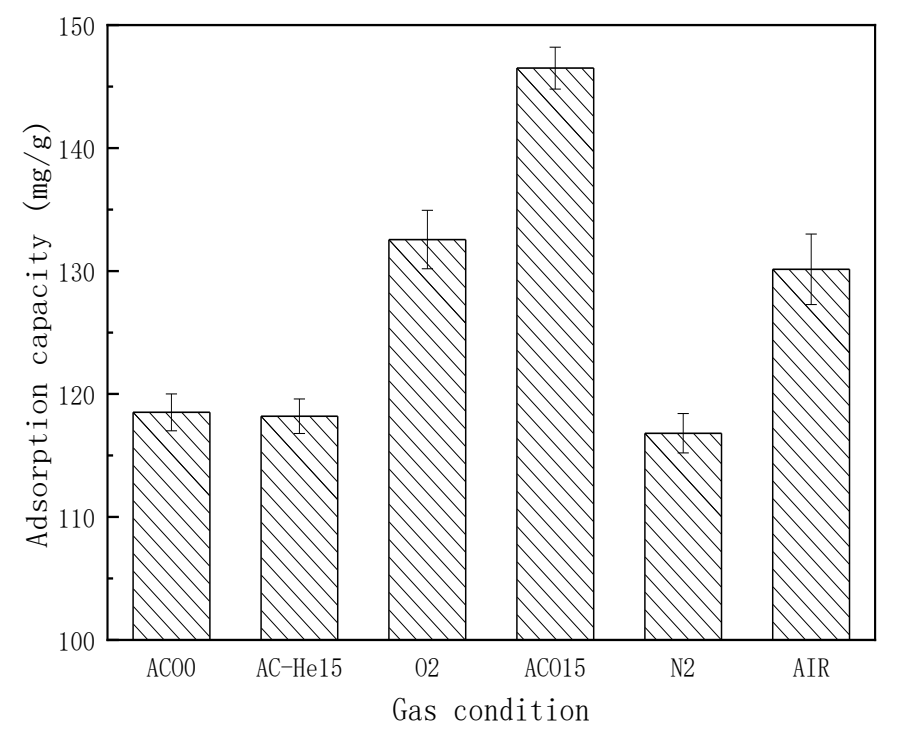

Fig. 8 Effect of different plasma modifications on the adsorption of aniline.

capacity of biochar after the oxygen-helium plasma treatment is greater than that of oxygen plasma and air plasma. This is because the addition of helium could stabilize the discharge of oxygen, and the plasma treatment effect was improved, so the biochar showed better aniline adsorption performance. ${ }^{[43]}$

\subsubsection{Effect of modification time on the adsorption of aniline}

As shown in Fig. 9, with the increase in modification time, the adsorption capacity of biochar to aniline first increased and then decreased. Unless otherwise specified, the modification conditions in this paper are $\mathrm{O}_{2}$-He plasma, modification for 15 $\mathrm{min}$, gas flow of $100 \mathrm{ml} / \mathrm{min}$, and discharge power of $48.8 \mathrm{~W}$. The adsorption amount reached the maximum at $15 \mathrm{~min}$, which was about $23.83 \%$ higher than the original biochar, and the removal rate reached about $73.12 \%$, indicating that the plasma-modified biochar had a good removal effect on lowconcentration aniline wastewater. With the increase in treatment time, more oxygen-containing functional groups were loaded on the biochar surface, and the adsorption amount continued to increase. ${ }^{[4]]}$ When the treatment time was further increased after $15 \mathrm{~min}$, the adsorption amount of the modified biochar began to decrease. The reason might be when the treatment time was too long, the functional groups on the surface of the biochar might ablate and the pores may collapse. ${ }^{[20]}$ This could be demonstrated by the $\mathrm{C}=\mathrm{O}$ decrease when the modification time was more than $15 \mathrm{~min}$. Therefore, the oxygen plasma modification had a certain degree of saturation, and the adsorption capacity of the biochar for aniline would decrease after a certain modification time.

\subsubsection{Effect of air flow rate on the adsorption of aniline}

As can be seen from Fig. 10, when the airflow rate was small, the adsorption capacity of biochar for aniline increased rapidly with the increase of airflow rate, reaching a maximum at 100

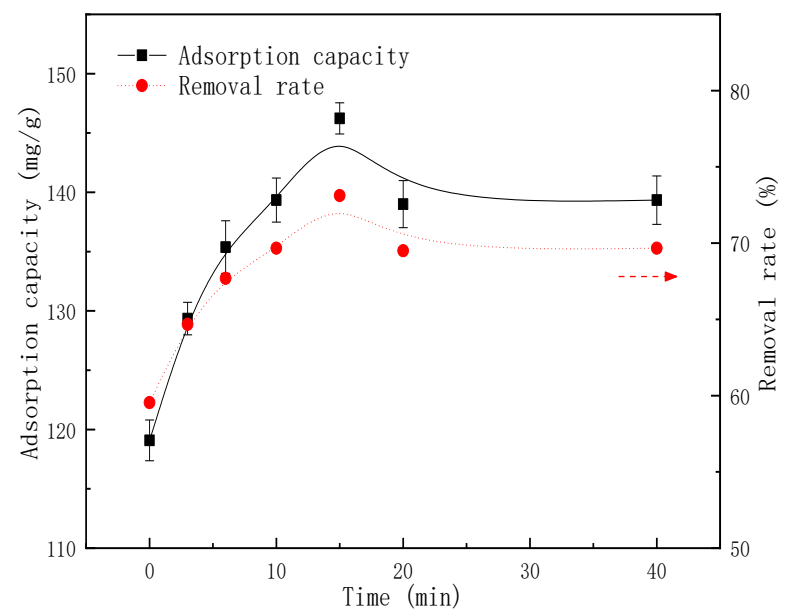

Fig. 9 Adsorption of aniline by samples with different modification times.

$\mathrm{mL} / \mathrm{min}$, when the airflow rate continued to increase, the adsorption amount of aniline on biochar decreased slowly. As the airflow increased, more gas was ionized, so the total amount of plasma increased and more reactive particles were available for the reaction. But at the same time, the shorter residence time of gas reduced the number of collisions of the electrons and active oxygen species with the surface of the biochar, which inhibited the modification process. ${ }^{[45]}$ Therefore, it could be concluded that the amount of plasma and the number of effective collisions of particles were in competition with each other and can be optimized by adjusting the gas flow rate.

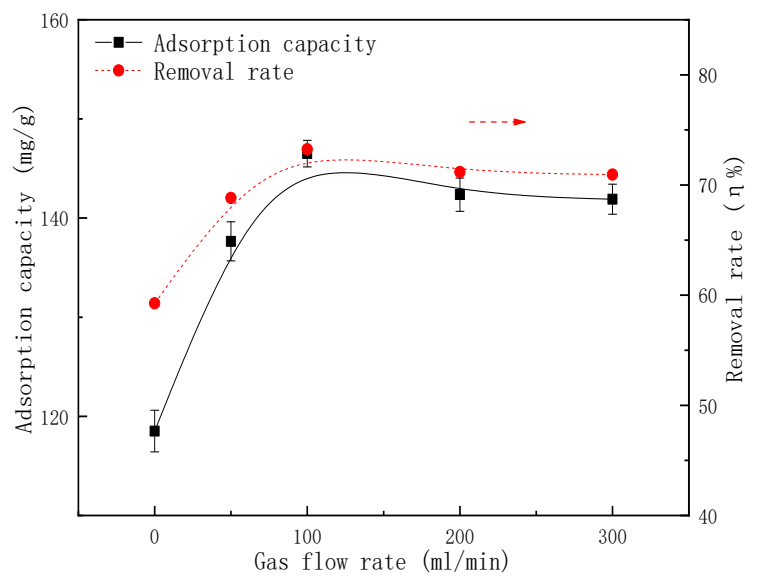

Fig. 10 Adsorption of aniline by the samples with different air flows.

\subsubsection{Effect of discharge power on adsorption of aniline}

Figure 11 shows the adsorption capacity of samples for aniline at a modified power of $34.9,48.8$, and $64.8 \mathrm{~W}$, corresponding to $34.0,36.0$, and $42.4 \mathrm{kV}$ peak-to-peak voltages respectively (voltage frequency was about $10.22 \mathrm{kHz}$ ). As the power increased, the adsorption amount of aniline to biochar first increased and then decreased. When the power was $48.8 \mathrm{~W}$, the adsorption reached a maximum of $147.24 \mathrm{mg} / \mathrm{g}$. When the power was $64.8 \mathrm{~W}$ and the peak-to-peak voltage was $42.4 \mathrm{kV}$, 
the adsorption capacity was reduced to $132.41 \mathrm{mg} / \mathrm{g}$. The higher peak-to-peak voltage caused a stronger electric field in the plasma region, which made the gas easier to be ionized and electrons to be generated greater kinetic energy after they accelerated in the electric field. ${ }^{[46]}$ When the power was appropriately increased, the generated plasma contained electrons of higher kinetic energy and more active particles such as $\bullet \mathrm{O}, \cdot \mathrm{OH}, \cdot \mathrm{OH}_{2}$, and $\mathrm{O}_{3}$, which can more effectively impinge against the surface of the biochar, causing atomic deposition to form a more functional group. However, the material had a certain tolerance. The results of the previous scanning electron microscope showed that when the power was too high, the surface of the material would be etched intensively, which would destroy the pore structure, and the reduction of specific surface area and pore volume would lead to a decreased in adsorption capacity.

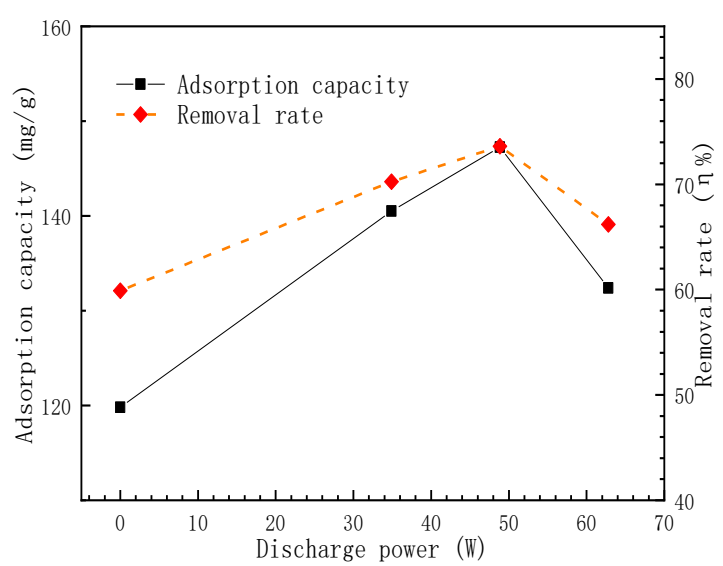

Fig. 11 Adsorption of aniline by samples with different discharge power.

\subsubsection{Dynamic adsorption experiments}

Figure 12 shows the results of the dynamic adsorption experiment of ACO0 and ACO15. When the outflow concentration is $90 \%$ of the original solution concentration, it is considered that the adsorption column bed has penetrated. It can be seen from the figure that the breakthrough time of $\mathrm{ACO} 0$ is $540 \mathrm{~min}$, and the breakthrough time of ACO15 is 800 $\min$. Therefore, it is believed that the modified biochar has a stronger adsorption potential.

\subsubsection{Adsorption kinetics and adsorption isotherm}

Figure 13 shows the Langmuir and Freundlich isothermal

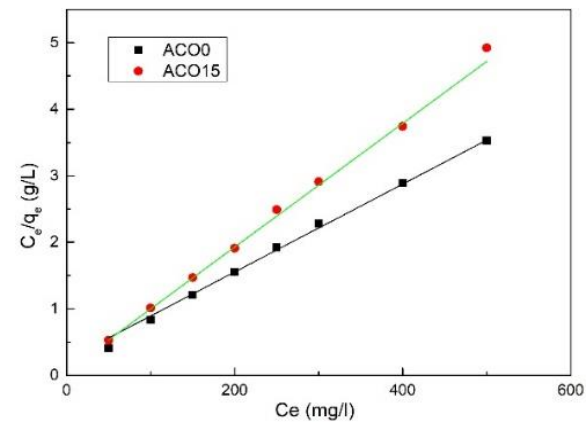

Fig. 13 Langmuir and Freundlich isothermal adsorption model of aniline for ACO0 and ACO15.

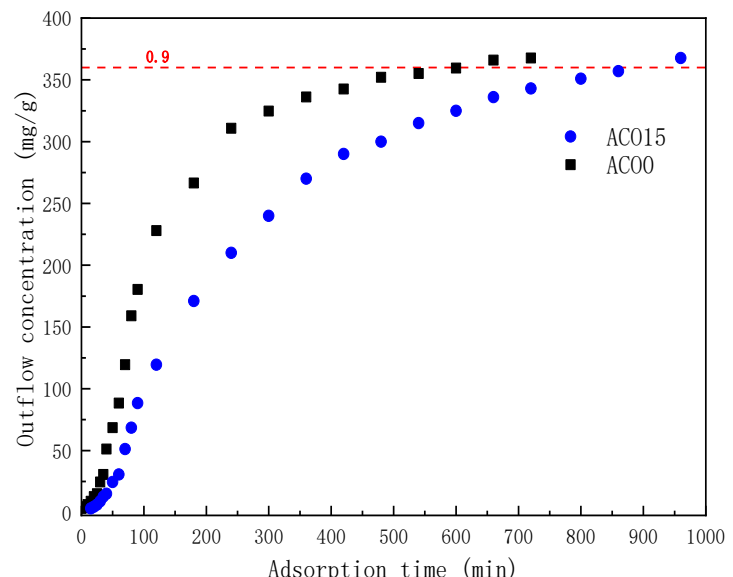

Fig. 12 Dynamic adsorption penetration curves of biochar before and after modification.

adsorption models of aniline adsorption at equilibrium concentration. The $\mathrm{R}^{2}$ values of the Langmuir model fitting for ACO0 and ACO15 were 0.9919 and 0.9916 , respectively, and the $\mathrm{R}^{2}$ values of the Freundlich model fitting were 0.9642 and 0.9645 , respectively. The Langmuir model showed a better linear relationship than the Freundlich model. According to the basic assumption of the Langmuir isothermal adsorption line, the adsorption of aniline on the modified biochar occurs on a relatively uniform surface, and the binding ability of the active sites on the surface of the material is similar. ${ }^{[4]}$ The adsorption is mainly monolayer adsorption, and the surface adsorption sites have high reactivity and strong adsorption capacity.

Figure 14 shows the relationship between the adsorption time and the adsorption capacity. The results show that the adsorption process was very rapid in the first $60 \mathrm{~min}$. With the increase of time, the adsorption capacity of both $\mathrm{ACO} 0$ and ACO15 increases. The adsorption capacity of ACO15 was significantly higher than that of ACO0, indicating that the removal effect of aniline from wastewater by biochar was improved by plasma modification at low temperatures. The adsorption plateau was reached at about $120 \mathrm{~min} \cdot{ }^{\left[{ }^{[8]}\right]}$ To further analyze the adsorption behaviors of aniline on ACO0 and ACO15, the pseudo-first-order and pseudo-second-order kinetic models were used to fit the experimental data. The fitting results are shown in Fig. 15. As shown in Table 5, the pseudo-first-order kinetic model fitting $\mathrm{R}^{2}$ values of $\mathrm{ACO} 0$ and ACO15 are 0.8946 and 0.8318 , respectively. As shown in

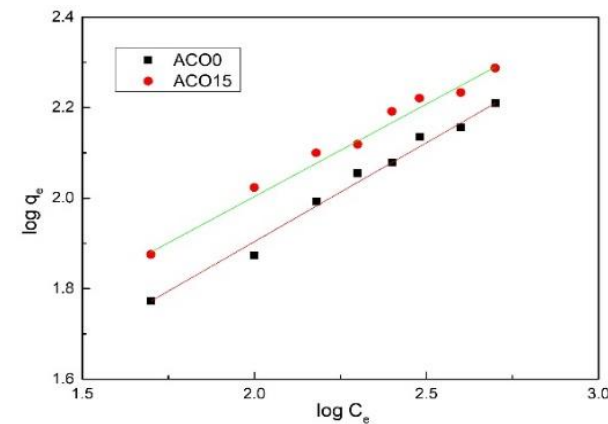




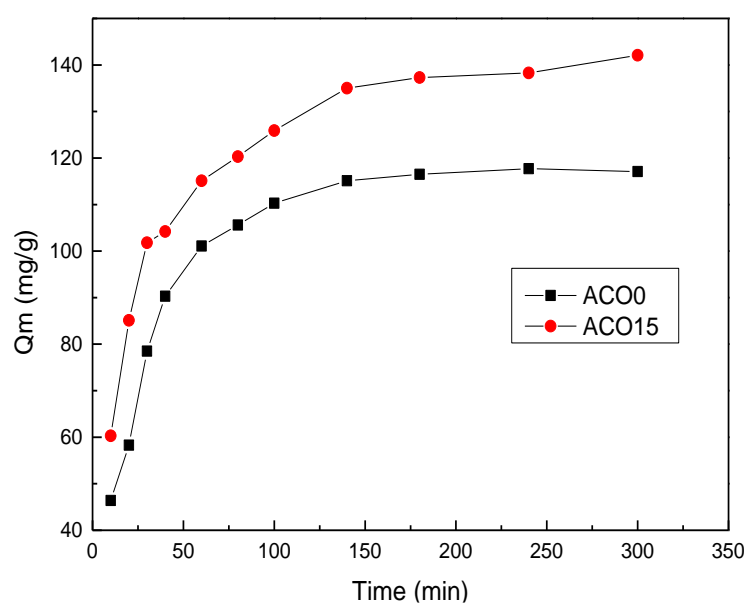

Fig. 14 Effect of adsorption time on adsorption capacity.

Table 6, the fitting factors of pseudo-second-order kinetics are 0.9987 and 0.9991 , respectively. Therefore, the pseudosecond-order kinetics model can better fit the experimental data.

Table 5. Pseudo first-order kinetic model.

\begin{tabular}{lllll}
\hline sample & $\begin{array}{l}\mathrm{q}_{\mathrm{e}, \mathrm{exp}} \\
(\mathrm{mg} / \mathrm{g})\end{array}$ & $\begin{array}{l}\mathrm{q}_{\mathrm{e}, \text { cal }} \\
(\mathrm{mg} / \mathrm{g})\end{array}$ & $\mathrm{k}_{1}$ & $\mathrm{R}^{2}$ \\
\hline ACO0 & 117.1 & 58.48 & 0.0174 & 0.8946 \\
$\mathrm{ACO} 15$ & 139.1 & 67.61 & 0.01815 & 0.8318 \\
\hline
\end{tabular}

Table 6. Pseudo second-order kinetic model.

\begin{tabular}{lllll}
\hline sample & $\begin{array}{l}\mathrm{q}_{\mathrm{e}, \mathrm{exp}} \\
(\mathrm{mg} / \mathrm{g})\end{array}$ & $\begin{array}{l}\mathrm{q}_{\mathrm{e}, \mathrm{cal}} \\
(\mathrm{mg} / \mathrm{g})\end{array}$ & $\mathrm{k}_{2}$ & $\mathrm{R}^{2}$ \\
\hline ACO0 & 117.1 & 128.8 & 0.0004087 & 0.9987 \\
$\mathrm{ACO} 15$ & 139.1 & 146.0 & 0.0004712 & 0.9991 \\
\hline
\end{tabular}

3.2.7 The possible mechanisms of modification and adsorption

It is well known that the adsorption of aniline is affected by physical adsorption and chemical adsorption. In this study, it can be found that ACO10 has a larger specific surface area and
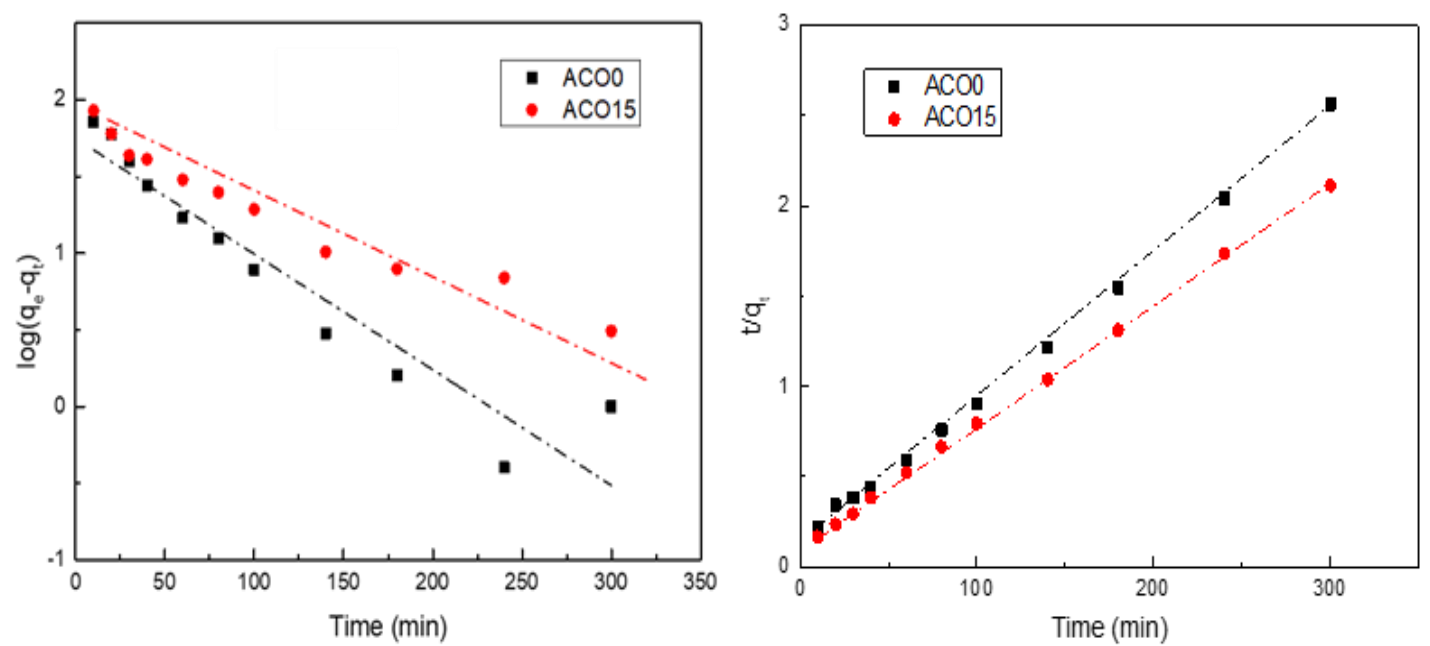

\subsection{Regeneration characteristic analysis}

\subsubsection{Effect of plasma parameters on regeneration}

As can be seen from Fig. 18, the gas composition has a great influence on the regeneration effect of deactivated biochar. Under the same treatment time, the order of regeneration ratio from large to small is oxygen/helium $(0.21: 0.79)>$ oxygen $>$ air $>$ helium $\geq$ nitrogen. When the treatment time was $90 \mathrm{~min}$, the regeneration ratio of oxygen/helium $(0.21: 0.79)$ was $85.11 \%$, and the regeneration ratio of oxygen was $67.48 \%$, which indicated that the addition of helium could improve the

Fig. 15 Pseudo first-order kinetic model and second-order kinetic model of aniline for ACO0 and ACO15. 


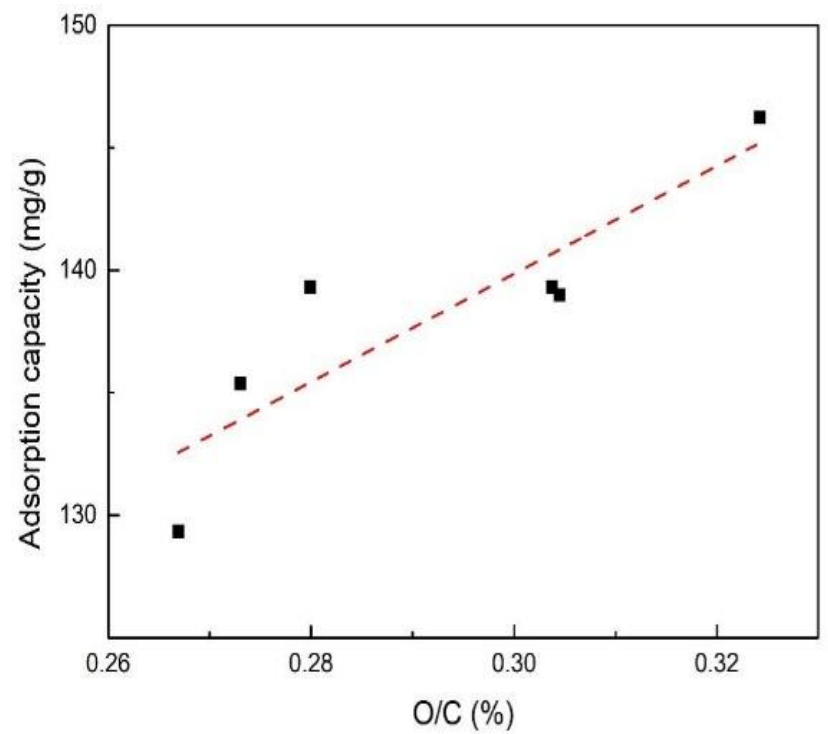

Fig. 16 The effect of the $\mathrm{O} / \mathrm{C}$ ratio on the aniline adsorption capacity of biochar.

regeneration ratio of the sample. However, when treated with helium plasma alone for $90 \mathrm{~min}$, the regeneration ratio was only $24.33 \%$, indicating that oxygen played a major role in the regeneration process of deactivated biochar by helium/oxygen (0.21:0.79) plasma. The regeneration ratio of air plasma treatment for $90 \mathrm{~min}$ was $64.44 \%$, while the regeneration ratio of nitrogen plasma treatment for the same time was $27.35 \%$, which also indicates that oxygen is an important factor determining the regeneration effect of low-temperature plasma.

As shown in Fig. 19, with the increase in load power, the regeneration speed presents a trend of constant growth, and the regeneration ratio also increases. When the treatment time was 0-30 min, aniline quickly decomposed and desorbed, and the pores blocked by aniline adsorption were exposed again. The adsorption capacity of the biochar recovered, and the regeneration ratio increased rapidly. The larger the load power, the larger the slope of the graph, indicating that the regeneration speed was faster. When the processing time was further increased to 30-90 $\mathrm{min}$, the regeneration ratio increased slowly and reached the maximum at $90 \mathrm{~min}$. But when the load power was $24.42 \mathrm{~W}$ with a processing time of $90 \mathrm{~min}$, the regeneration ratio was only $52 \%$, this was because the lower the load power, the less energy input per unit area, the lower the corresponding electric field intensity, and the lower, less ionized oxygen molecules per unit of time. When the load power was $40.7 \mathrm{~W}$, the regeneration ratio increased to $72.75 \%$, and when the load power values were $56.98 \mathrm{~W}, 65.12$ $\mathrm{W}$, and $73.26 \mathrm{~W}$, the regeneration ratios were all about $85 \%$.

\subsubsection{Effect of water vapor addition on regeneration}

Different adding methods of $\mathrm{H}_{2} \mathrm{O}$ have different regeneration rules and effects. The regeneration ratio of deactivated biochar was improved by adding water vapor under plasma conditions. This is because more hydroxyl free radicals can be generated in the plasma. The strong oxidizability of hydroxyl free radicals gave the plasma a stronger oxidation capacity, which improves the removal rate of aniline on the biochar and significantly improves the regeneration ratio. The premixed of biochar and water causes water molecules to block the pore of biochar, and the adsorbate inside cannot be effectively removed, so the regeneration ratio is greatly reduced. As shown in Fig. 20(b), with the increase of the water/biochar mass ratio, the regeneration ratio showed a trend of first increasing and then decreasing slowly. Because when the water quantity was low, the increase of water vapor flow rate would increase the number of hydroxyl radicals in the plasma, and the regeneration ratio will increase. However, at the same time, increasing the amount of water would lower the discharge power, which had an inhibitory effect on gas discharge. Therefore, when the amount of water was too much, the plasma production would decrease, thus reducing the regeneration ratio.

\subsubsection{Comparison of thermal regeneration and plasma regeneration}

The experiments of thermal regeneration and plasma regeneration of saturated biochar were carried out under optimal experimental conditions. As can be seen from Fig. 21, when the number of regenerations was relatively small, both

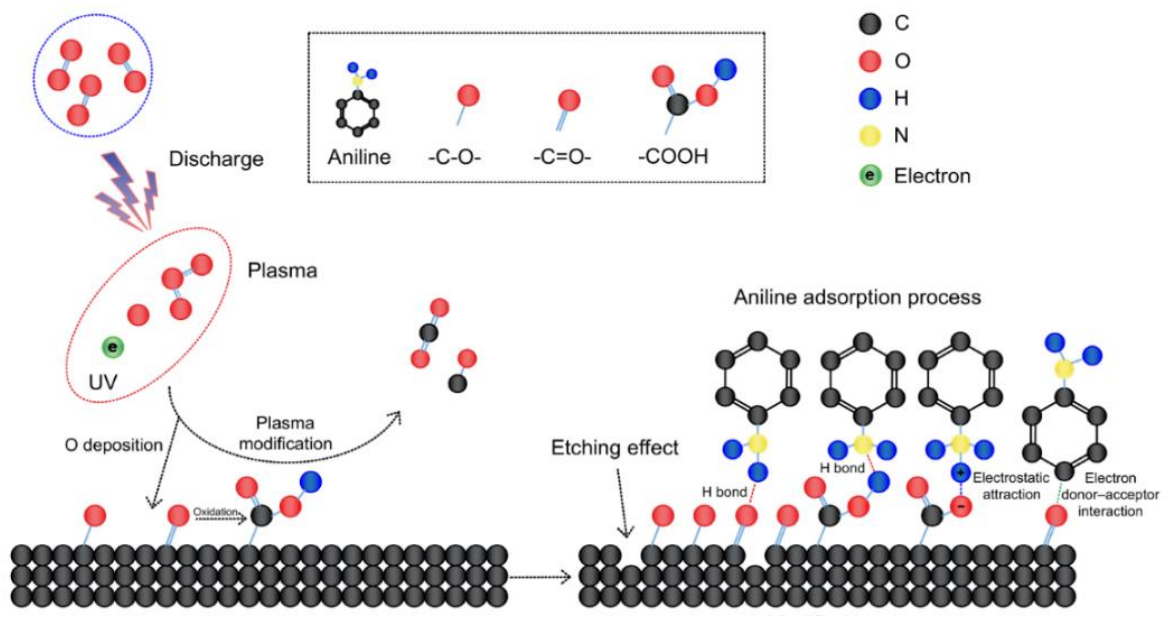

Fig. 17 Plasma modification and aniline adsorption mechanism diagram. 


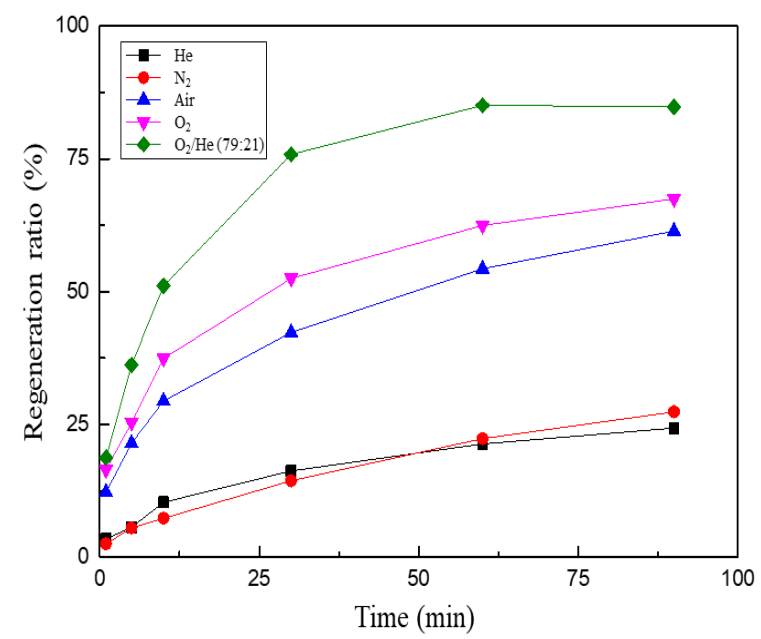

Fig. 18 Effect of gas composition on regeneration of biochar plasma.

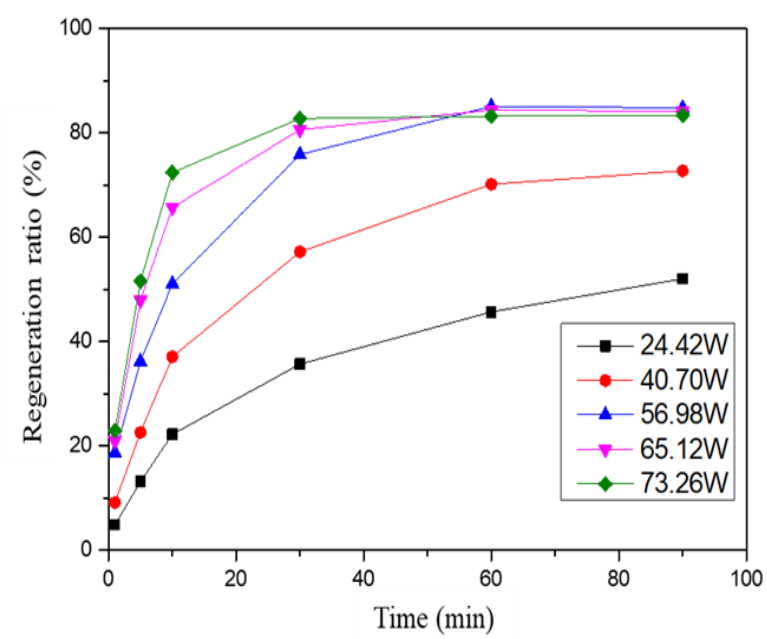

Fig. 19 Effect of load power on biochar plasma regeneration.

methods maintain a high regeneration ratio. Regeneration after 10 times, the low-temperature plasma regeneration ratio remained above $80 \%$. However, the thermal regeneration ratio was only $55.28 \%$. After 10 times of thermal regeneration, the structure of the biochar was seriously damaged, and the biochar was fractured and fragmented. The pores collapsed in large numbers, the adsorption capacity of biochar was

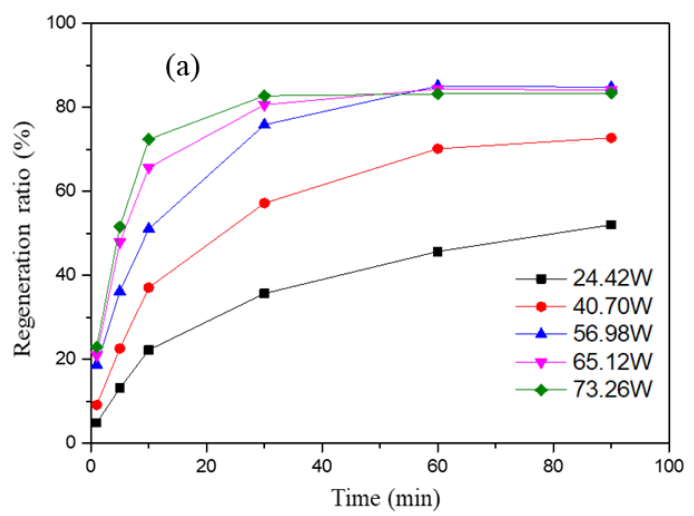

inhibited and a sharp decline in the regeneration ratio appeared. With the increase in regeneration times, the regeneration advantage of low-temperature plasma was more obvious, and the regeneration ratio remained high after repeated regeneration.

The variation of the pore structure of the biochar with the number of plasma regeneration is shown in Table 7. The specific surface area and pore volume of the biochar were significantly lower when saturated by the absorbent. After a regeneration, the adsorbate on the surface was desorbed and the pore structure of the biochar was restored. The pores were rebuilt and the specific surface area increased slightly. With the increase of number of regeneration cycles, the pores of the biochar collapsed in the process of regeneration. In the competition between pore-making and pore-destroying, the pore destruction gradually became dominant, and the specific surface area and pore volume both decreased. However, the overall structure of biochar remained intact after repeated regeneration. After ten regeneration cycles, the specific surface area decreased to $712.45 \mathrm{~m}^{2} / \mathrm{g}$, which was $78.4 \%$ of the initial value, and the total pore volume decreased to 0.703 , $81.7 \%$ of the initial value. Therefore, the regeneration ratio was still relatively high.

\section{Conclusion}

In this study, oxygen-helium non-thermal plasma was used to modify and regenerate biochar. The oxygen plasma treatment increased the oxygen content of the biochar, and the FTIR and XPS showed that the $\mathrm{C}-\mathrm{O}, \mathrm{O}-\mathrm{C}=\mathrm{O}$, and $\mathrm{C}=\mathrm{O}$ functional groups increased. After modification, the adsorption capacity of aniline increased from $118.1 \mathrm{mg} / \mathrm{g}$ to $146.5 \mathrm{mg} / \mathrm{g}$, which was a $23.8 \%$ increase. The adsorption mechanism was assumed to be the oxygen of $\mathrm{C}=\mathrm{O}$ forms a hydrogen bond with the hydrogen on the aniline amino group, and the hydrogen on the carboxyl group formed a hydrogen bond with the nitrogen on the aniline amino group. The electrostatic interaction of the protonated amino and carboxyl groups and the carbonyl group formed an electron donor-acceptor structure with the aromatic ring of aniline. Compared with thermal regeneration, the regenerative advantage of the low-temperature plasma becomes more and more significant with the increase in

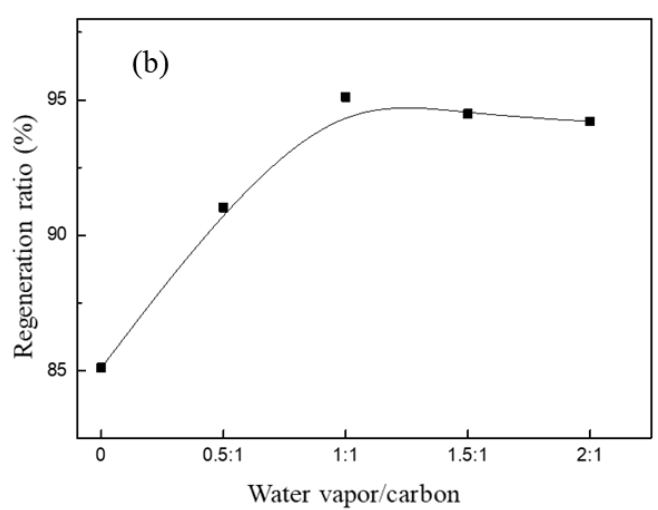

Fig. 20 Effect of water addition method (a) and amount (b) on regeneration of biochar plasma. 


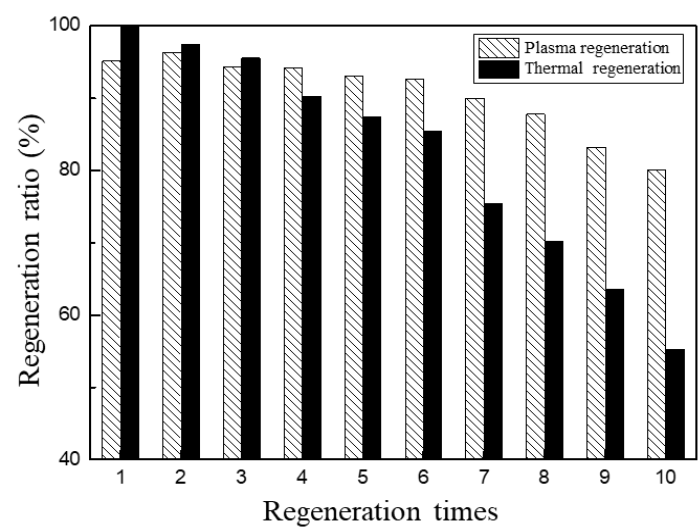

Fig. 21 Comparison of thermal regeneration and plasma regeneration.

Table 7. Pore structure change of biochar regenerated by plasma.

\begin{tabular}{lccc}
\hline sample & $\begin{array}{c}\mathrm{S}_{\mathrm{BET}} \\
\left(\mathrm{m}^{2} / \mathrm{g}\right)\end{array}$ & $\begin{array}{c}\text { Total pore volume } \\
\left(\mathrm{cm}^{3} / \mathrm{g}\right)\end{array}$ & $\begin{array}{c}\text { Average } \\
\text { aperture } \\
(\mathrm{nm})\end{array}$ \\
\hline $\begin{array}{l}\text { ACO15 } \\
\text { Saturated }\end{array}$ & 908.17 & 0.860 & 4.31 \\
ACO15 & 477.58 & 0.507 & 4.24 \\
1st cycle & 923.21 & 0.857 & 4.38 \\
2nd cycle & 886.89 & 0.835 & 4.42 \\
3rd cycle & 876.01 & 0.814 & 4.47 \\
10th cycle & 712.45 & 0.703 & 4.98 \\
\hline
\end{tabular}

regeneration times. Oxygen-helium non-thermal plasma modification is a simple, environmentally friendly, and effective technique for improving the adsorption of biochar, and therefore has very broad prospects.

\section{Acknowledgments}

The authors acknowledge the financial support of the National Natural Science Foundation of China (Grant Nos. 51822604).

\section{Conflict of Interest}

There is no conflict of interest.

\section{Supporting Information}

Not Applicable.

\section{References}

[1] Y. Jiang, L. Wei, K. Yang, H. Wang, Science of the Total Environment, 2019, 646, 841-849, doi: 10.1016/j.scitotenv.2018.07.313.

[2] U. Beker, B. Ganbold, H. Dertli, D. D. Gülbayir, Energy Conversion and Management, 2010, 51, 235-240, doi: 10.1016/j.enconman.2009.08.035.

[3] Y. He, H. Lin, Z. Guo, W. Zhang, H. Li, W. Huang, Separation and Purification Technology, 2019, 212, 802-821, doi: 10.1016/j.seppur.2018.11.056.
[4] K. Yang, L. Zhu, J. Yang, D. Lin, Science of the Total Environment, 2018, 618, 1677-1684, doi: 10.1016/j.scitotenv.2017.10.018.

[5] N. B. Singh, G. Nagpal, S. Agrawal, Rachna, Environmental Technology \& Innovation, 2018, 11, 187-240, doi: 10.1016/j.eti.2018.05.006.

[6] A. K. Ayoob, A. B. Fadhil, Energy Conversion and Management, 2019, 201, 112149, doi: 10.1016/j.enconman.2019.112149.

[7] H. Zhang, X. Yue, F. Li, R. Xiao, Y. Zhang, D. Gu, Science of the Total Environment, 2018, 631-632, 795-802, doi: 10.1016/j.scitotenv.2018.03.071.

[8] M. Salimi, Z. Salehi, H. Heidari, F. Vahabzadeh, Journal of Environmental Chemical Engineering, 2021, 9, 105403, doi: 10.1016/j.jece.2021.105403.

[9] W. Yang, H. Chen, X. Han, S. Ding, Y. Shan, Y. Liu, Journal of Hazardous Materials, 2020, 381, 120981, doi: 10.1016/j.jhazmat.2019.120981.

[10] J. Rivera-Utrilla, M. Sánchez-Polo, Carbon, 2002, 40, 2685 2691, doi: 10.1016/s0008-6223(02)00182-3.

[11] D. P. Wilcox, E. Chang, K. L. Dickson, K. R. Johansson, Applied and Environmental Microbiology, 1983, 46, 406-416, doi: 10.1128/aem.46.2.406-416.1983.

[12] A. Bhatnagar, W. Hogland, M. Marques, M. Sillanpää, Chemical Engineering Journal, 2013, 219, 499-511, doi: 10.1016/j.cej.2012.12.038.

[13] N. Qiang, J. Luo, Y. Xia, S. Sun, C. Qiang, Fuel Processing Technology, 2017, 156, 310-316, doi: 10.1016/j.fuproc.2016.09.013.

[14] Y. Xu, G. Luo, Q. Pang, S. He, F. Deng, Y. Xu, H. Yao, Chemical Engineering Journal, 2019, 358, 1454-1463, doi: 10.1016/j.cej.2018.10.145.

[15] I. Adamovich, S. D. Baalrud, A. Bogaerts, P. J. Bruggeman, M. Cappelli, V. Colombo, U. Czarnetzki, U. Ebert, J.G. Eden, P. Favia, Journal of Physics D: Applied Physics, 2017, 50, 323001, doi: 10.1088/1361-6463/aa76f5.

[16] E. Robert, T. Darny, S. Dozias, S. Iseni, J. M. Pouvesle, Physics of Plasmas, 2015, 22, 122007, doi: 10.1063/1.4934655.

[17] B. M. Obradović, S. S. Ivković, M. M. Kuraica, Applied Physics Letters, 2008, 92, 191501, doi: 10.1063/1.2927477.

[18] P. Ning, S. Liu, C. Wang, K. Li, X. Sun, L. Tang, G. Liu, Journal of Environmental Sciences, 2018, 64, 216-226, doi: 10.1016/j.jes.2017.06.017.

[19] A. Wang, J. H. Harrhy, S. Meng, P. He, L. Liu, H. Song, Energy Conversion and Management, 2019, 191, 93-101, doi: 10.1016/j.enconman.2019.04.026.

[20] R. Brandenburg, Plasma Sources Science and Technology, 2017, 26, 53001, doi: 10.1088/1361-6595/aa6426.

[21] Y. W. Huang, Q. F. Yu, M. Li, S. N. Sun, H. Zhao, S. X. Jin, J. Fan, J. G. Wang, Plasma Processes and Polymers, 2020, 18, 2000171, doi: 10.1002/ppap.202000171.

[22] R. Hu, J. Xiao, T. Wang, Y. Gong, G. Chen, L. Chen, X. Tian, Carbon, 2020, 168, 515-527, doi: 10.1016/j.carbon.2020.07.012. 
[23] L. Wu, Y. Cai, J. Tu, S. Wang, N. Kobayashi, Z. Li, International Journal of Chemical Reactor Engineering, 2020, 18 20190192, doi: 10.1515/ijcre-2019-0192.

[24] M. Shi, G. Luo, Y. Xu, R. Zou, H. Zhu, J. Hu, X. Li, H. Yao, Fuel, 2019, 254, 115549, doi: 10.1016/j.fuel.2019.05.132.

[25] J. L. Chung, H. L. Dae, K. Taegyu, Catalysis Today, 2017, 293, 97-104, doi: 10.1016/j.cattod.2017.01.022.

[26] A. Bourdon, T. Darny, F. Pechereau, J. M. Pouvesle, P. Viegas, S. Iséni, E. Robert, Plasma Sources Science and Technology, 2016, 25, 035002, doi: 10.1088/09630252/25/3/035002.

[27] A. Bourdon, F. Péchereau, F. Tholin, Z. Bonaventura, Journal of Physics D: Applied Physics, 2021, 54, 075204, doi: 10.1088/1361-6463/abbc3a.

[28] Q. Li, W. Zhu, X. Zhu, Y. Pu, Journal of Physics D: Applied Physics, 2010, 43, 382001, doi: 10.1088/00223727/43/38/382001.

[29] A. A. Heneral, S. V. Avtaeva, Journal of Physics D: Applied Physics, 2020, 53, 195201, doi: 10.1088/1361-6463/ab7354.

[30] D. Mei, X. Zhu, Y.-L. He, J. D. Yan, X. Tu, Plasma Sources Science and Technology, 2014, 24, 015011, doi: 10.1088/09630252/24/1/015011.

[31] L. Wu, W. Wan, Z. Shang, X. Gao, N. Kobayashi, G. Luo, Z. Li, Separation and Purification Technology, 2018, 197, 156-169, doi: 10.1016/j.seppur.2018.01.007.

[32] Y. Yang, D. Zhang, Q. Xiang, Nanoscale, 2019, 11, $18797-$ 18805, doi: 10.1039/c9nr07242j.

[33] R. Paneru, S. H. Ki, P. Lamichhane, L. N. Nguyen, B. C. Adhikari, I. J. Jeong, S. Mumtaz, J. Choi, J. S. Kwon, E. H. Choi, Applied Surface Science, 2020, 532, 147339, doi: 10.1016/j.apsusc.2020.147339.

[34] C. J. Powell, A. Jablonski, Journal of Electron Spectroscopy and Related Phenomena, 2010, 178, 331-346, doi: 10.1016/j.elspec.2009.05.004.

[35] S. M. Yakout, G. Sharaf El-Deen, Arabian Journal of Chemistry, 2016, 9, S1155-S1162, doi: 10.1016/j.arabjc.2011.12.002.

[36] M. S. Alam, D. Gorman-Lewis, N. Chen, S. L. Flynn, Y. S. Ok, K. O. Konhauser, D. S. Alessi, Environmental Science \& Technology, 2018, 52, 6246-6255, doi: 10.1021/acs.est.7b06261. [37] X. Sun, J. Bao, K. Li, M.D. Argyle, G. Tan, H. Adidharma, K. Zhang, M. Fan, P. Ning, Advanced Functional Materials, 2020, 31, 2006287, doi: 10.1002/adfm.202006287.

[38] J. Ackermann, A. Krueger, Carbon, 2020, 163, 56-62, doi: 10.1016/j.carbon.2020.02.088.

[39] Z. Zhou, Z. Cheng, L. Zhuo, W. Yuan, Chemical Engineering Journal, 2008, 136, 414-418, doi: 10.1016/j.cej.2007.06.018.

[40] L. Wu, Z. Shang, S. Chen, J. Tu, N. Kobayashi, Z. Li, RSC Advances, 2018, 8, 21993-22003, doi: 10.1039/c8ra03271h.

[41] J. I. Mendez-Linan, E. Ortiz-Ortega, M. F. Jimenez-Moreno, M. I. Mendivil-Palma, E. Martínez-Guerra, F. S. Aguirre-Tostado, S. O. Martinez-Chapa, S. Hosseini, M. J. Madou, Carbon, 2020, 169, 32-44, doi: 10.1016/j.carbon.2020.06.085.

[42] H. Li, L. Liu, J. Cui, J. Cui, F. Wang, F. Zhang, RSC Advances, 2020, 10, 14262-14273, doi: 10.1039/d0ra01245a.
[43] R. Hu, J. Xiao, T. Wang, Y. Gong, G. Chen, L. Chen, X. Tian, Carbon, 2020, 168, 515-527, doi: 10.1016/j.carbon.2020.07.012. [44] O. González-Cordero, L. E. Cruz-Barba, S. A. Gómez-Torres, F. R. Carrillo-Pedroza, C. D. R. Arellano del Rio, M. A. SánchezCastillo, Carbon, 2018, 126, 552-565, doi: 10.1016/j.carbon.2017.10.037.

[45] Y. Gao, S. Zhang, H. Sun, R. Wang, X. Tu, T. Shao, Applied Energy, 2018, 226, 534-545, doi: 10.1016/j.apenergy.2018.06.006.

[46] O. Khalifeh, A. Mosallanejad, H. Taghvaei, M. R. Rahimpour, A. Shariati, Applied Energy, 2016, 169, 585-596, doi: 10.1016/j.apenergy.2016.02.017.

[47] Y. Zeng, Z. Zeng, T. Ju, F. Zhang, Microporous and Mesoporous Materials, 2015, 210, 60-68, doi: 10.1016/j.micromeso.2015.02.021.

[48] Y. Liu, P. Wu, F. Liu, F. Li, X. An, J. Liu, Z. Wang, C. Shen, W. Sand, Environmental Science \& Technology, 2019, 53, 1527 1535, doi: 10.1021/acs.est.8b05936.

[49] C. Shen, G. Song, G. Tang, Surface and Coatings Technology, 2018, 354, 126-133, doi: 10.1016/j.surfcoat.2018.09.010.

[50] L. Zuo, W. Song, T. Shi, C. Lv, J. Yao, J. Liu, Y. Weng, Microporous and Mesoporous Materials, 2014, 200, 174-181, doi: 10.1016/j.micromeso.2014.08.036.

[51] J. A. Mattson, H. B. Mark Jr, M. D. Malbin, W. J. Weber Jr, J. C. Crittenden, Journal of Colloid and Interface Science, 1969, 31, 116-130, doi: 10.1016/0021-9797(69)90089-7.

[52] T. Sizmur, T. Fresno, G. Akgül, H. Frost, E. Moreno-Jiménez, Bioresource Technology, 2017, 246, 34-47, doi: 10.1016/j.biortech.2017.07.082.

\section{Author information}

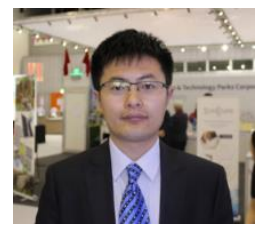

Dr. Huiyan Zhang is a professor and deputy dean of School of Energy and Environment at Southeast University. His research focuses on biomass conversion into value-added products including transportation fuels, chemicals and carbon materials. At present he is (co-)author of 4 international and 40 Chinese patents and over 90 international papers (Indexed by SCI) including that published in Science, Energy \& Environmental Science. His work has been cited by SCI index more than 3000 times. Prof. Zhang is the winner of the National Nature Science Fund of China for Excellent Young Scholar. He obtained 4 national and international prizes including the first prize of natural science of Ministry of Education, special gold medal of Geneva international inventions Exhibition. He serves as Editorial Board or Guest Editor of 8 Journals, such as Fuel processing Technology, Science of The Total Environment, and so on.

Publisher's Note: Engineered Science Publisher remains neutral with regard to jurisdictional claims in published maps and institutional affiliations 